\title{
European symposium on precision medicine in allergy and airways diseases: report of the European Union parliament symposium (October 14, 2015)*
}

\author{
A. Muraro', W.J. Fokkens², S. Pietikainen³, D. Borrelli³, I. Agache', \\ J. Bousquet ${ }^{4}$, V. Costigliola ${ }^{5}$, G. Joos ${ }^{6}$, V.J. Lund ${ }^{2}$, L.K. Poulsen' ${ }^{1}$, D. Price', \\ C. Rolland ${ }^{8}$, T. Zuberbier ${ }^{9}$, P.W. Hellings ${ }^{1}$

Rhinology 54: 303-307, 2016 DOl:10.4193/Rhino15.400 *Received for publication:

\begin{abstract}
On 14 October 2015, the European Academy of Allergy and Clinical Immunology (EAACI), the European Rhinologic Society (ERS) and the European Medical Association (EMA) organized a symposium in the European Parliament in Brussels on Precision Medicine in Allergy and Airways Diseases, hosted by MEP David Borrelli and with active participation of the European Respiratory Society (ERS), the European Federations of Allergy and Airways Diseases Patients Associations (EFA), the Global Allergy and Asthma European Network (Ga2len), Allergic Rhinitis and Its Impact on Asthma (ARIA) and the Respiratory Effectiveness Group (REG). MEP Sirpa Pietikainen, Chair of the European Parliament Interest Group on Allergy and Asthma, underlined the importance of the need for a better diagnostic and therapeutic approach for patients with Allergies and Chronic Airways Diseases, and encouraged a joint initiative to control the epidemic of Allergy and Asthma in Europe. The socio-economic impact of allergies and chronic airways diseases cannot be underestimated, as they represent the most frequently diagnosed chronic non-communicable diseases in the EU. Despite the fact that $30 \%$ of the total European population is nowadays suffering from allergies and asthma, more than half of these patients are deprived from adequate diagnosis and treatment. Precision Medicine represents a novel approach in medicine, embracing 4 key features: personalized care based on molecular, immunologic and functional endotyping of the disease, with participation of the patient in the decision making process of therapeutic actions, and taking into account predictive and preventive aspects of the treatment. Implementation of Precision Medicine into clinical practice may help to achieve the arrest of the Epidemic of Allergies and Chronic Airways Diseases.

This report summarizes the key messages delivered during the symposium by the speakers, including the EU Commissioner for Health and Food Safety Vitenys Andriukaitis. The Commissioner underscored the need for optimal patient care in Europe, supporting joint action plans for disease prevention, patient empowerment and cost-effective treatment strategies leading to a better health status of European citizens.
\end{abstract}

Key words: precision medicine, allergy, airways diseases, personalized care, prevention 


\section{Introduction}

Chronic respiratory diseases (CRDs) and allergic diseases (e.g. asthma, rhinitis, COPD and rhinosinusitis) represent a global health problem ${ }^{(1)}$. They affect over 1 billion people of all ages and are increasing in prevalence and severity ${ }^{(2)}$. They are insufficiently diagnosed and controlled leading to unbearable societal and economic consequences. Prevention, early diagnosis and control of CRDs represent a priority of the $\mathrm{EU}^{(3)}$.

Precision medicine is a medical model aiming to deliver customised healthcare with medical decisions, practices, and/ or products tailored to the individual patient informed but not directed by guidelines ${ }^{(4)}$. This model is associated with patient stratification and socio-economic savings ${ }^{(5)}$. Precision medicine is fundamental in allergology and has been used for over a century in the diagnosis and treatment of allergic diseases ${ }^{(6,7)}$. Precision medicine is a medical technology which is evolving rapidly with new diagnostic tools allowing endotoping and new therapeutic options. Complemented by e-health, it will change the way medicine is practiced ${ }^{(8)}$.

14 October 2015, the European Academy of Allergy and Clinical Immunology (EAACI), the European Rhinologic Society (ERS) and the European Medical Association (EMA) organized a symposium at the European parliament in Brussels on precision medicine in allergy and airways diseases, hosted by MEP David Borrelli and with active participation of the Interest Group on Allergy and Asthma of the European parliament presided by MEP Sirpa Pietikainen, the European Rhinologic Society (ERS), the European Federations of Allergy and Airways Diseases Patients Associations (EFA), the Global Allergy and Asthma European Network (Ga2len), Allergic Rhinitis and Its Impact on Asthma (ARIA), the Respiratory Effectiveness Group (REG) and the European Innovation Partnership on Active and Healthy Ageing Reference Site ${ }^{(9)}$ (Figure 1).

A meeting discussed how precision medicine will increase the

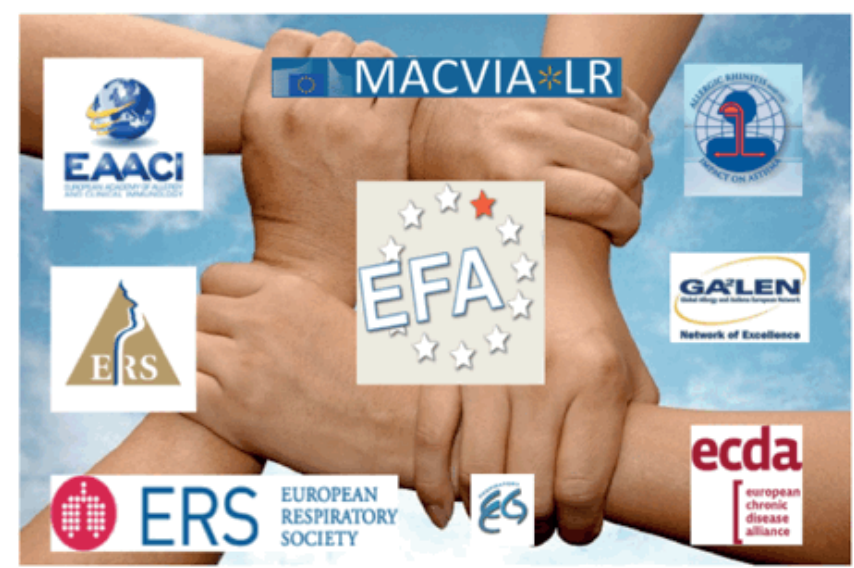

Figure 1. Joining forces in Europe by different Academies and Socieities to arrest the Epidemic of Allergy and Chronic Airways Diseases. knowledge on airway diseases, their prevention, early detection and appropriate management in order to propose innovative solutions for improving the socio-economic challenge across the life cycle, and ultimately to promote active and healthy ageing (10).

\section{Current challenges of allergies and chronic respira- tory diseases in Europe (Figure 2)}

- One third of the population in Europe is suffering from Allergies and $\mathrm{CRDs}^{(3)}$, with a prevalence reaching $40 \%$ in the population under the age of 60 .

- Allergies and CRDs often begin early in life, and persist throughout the life cycle, affecting all age groups (12) (13)

- Rhinitis and asthma are the most common diseases in childhood and asthma is the most common cause of hospitalization in this age group. Early detection, prevention and management are important ${ }^{(5)}$.

- Asthma and rhinitis are common in the elderly ${ }^{(14)}$, and probably cause serious problems but there is insufficient information in this age group.

- Risk factors for Allergies and CRDs are known, including allergens, tobacco smoke, and outdoor and indoor pollution (air quality) ${ }^{(3)}$. Health promotion and prevention strategies should be better implemented across policy areas.

- Quality of life is severely impaired in patients suffering from chronic upper (rhinitis and rhinosinusitis) ${ }^{(15)}$ and lower airway diseases (asthma and COPD) ${ }^{(16)}$.

- These diseases affect work ${ }^{(17,18)}$ and school performance ${ }^{(19)}$. Fit at work with allergic or CRD should be implemented to maintain the population at work. Improved educations of children with allergic and CRDs and of their caregivers, including school environment is another priority ${ }^{(12)}$.

- Allergies and CRDs remain largely underdiagnosed and undertreated, despite the availability of effective and safe treatment options, and despite the availability of evidencebased guidelines for treatment. Health technology assessment is needed ${ }^{(8)}$.

- Different health care providers are involved in the diagnostic and therapeutic approach of patients with Allergies and CRDs: pharmacists, general practicioners and specialists, nurses and specialists, involving otorhinolaryngologists, pneumologists, paediatricians, and allergologists. However, most patients consult in primary care or in community pharmacies.

- Language used by healthcare professionals in communicating to patients needs to be examined, and adequate guidelines and training provided, if patients are to be fully empowered in the management of their condition.

- Integrated care pathways should be developed with an optimal interaction between health care providers and patients ${ }^{(10)}$ to allow an appropriate cost-stratification. 


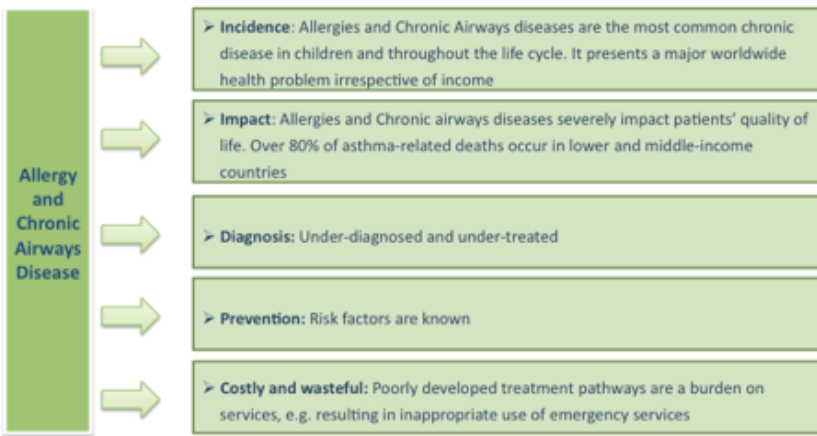

Figure 2. Current challenges in relation to Allergies and Chronic Airways Diseases.
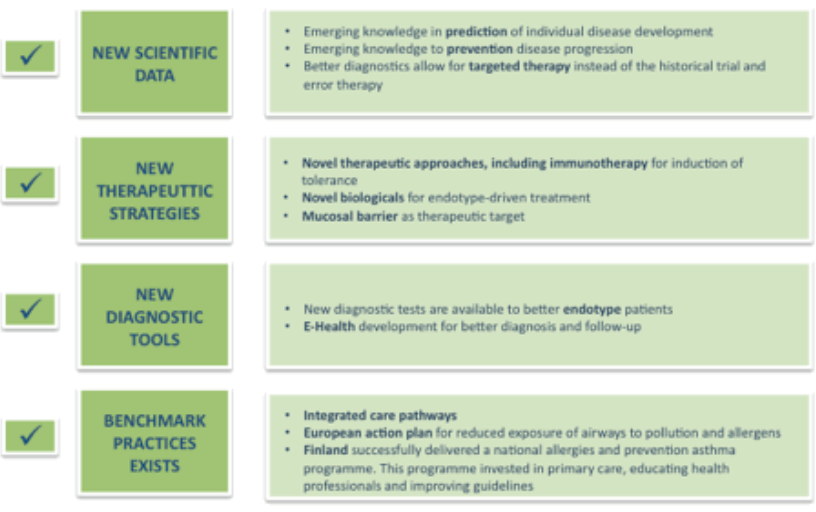

Figure 3. Current challenges in relation to Allergies and Chronic Airways Diseases.
E-health is an important component of care pathways.

- The socio-economic impact of Allergies and CRDs is enormous. Poorly developed treatment strategies are costly and wasteful. The economic burden on inadequate treatment of allergic diseases in Europe has been estimated to exceed $50 \mathrm{~B} €$ per year in Europe ${ }^{(20)}$. Indirect costs largely exceed the direct costs, and are mainly related to absenteeism and presenteism (21).

- Teaching and coaching should be developed at the global level and then disseminated at the local level.

- Allergic and CRDs are changing due to epidemiologic, health care and socio-economic factors, and climate change. There is an urgent need for a sustained resilience plan proposed by all stakeholders.

\section{Joint and innovative action plan at the EU level}

- In order to prevent fragmentation and to improve the costeffectiveness of an action plan:

- Identified challenges need to be tackled at the EU level and then scaled up at the national and regional levels for dissemination and implementation.

- All stakeholders involved in CRD and allergy care should agree on a joint action plan including care pathways, as also outlined in the EAACI Strategic Program 2015-2017 http://www.eaaci.org/organisation/eaacistrategic-programme/2013-2015.html (22)

- We need to advocate for the status of a full specialty of allergology, harmonised across all European countries ${ }^{(22)}$

- Innovative solutions are needed at all levels: prevention, early diagnosis and management, and education.

- Patients and their representative organisations need to be at the centre of this action plan. ${ }^{(22)}$

- The goals are:

- To curb the Epidemic of allergic and CRDs.

- To improve the health of the European population affected by these diseases. A target of $30 \%$ reduction in disease burden within the next 10 years should be achieved.

- The action plan is based on:

- New scientific data are emerging allowing prediction and prevention ${ }^{(23)}$.

- Novel diagnostic tools are emerging, allowing better immunologic and functional endotyping of the patient (13) (24). Component Resolved Diagnosis (CRD) allows the evaluation of the individual sensitization pattern to environmental allergens ${ }^{(25,26)}$. Nasal hyperrreactivity (NHR) can be diagnosed $^{(27)}$. Novel e-health tools allow for better phenotyping and therapeutic follow-up of patients.

- Novel therapeutic strategies, such as endotype driven approach, are emerging allowing the design of novel therapeutic strategies, including allergen immunotherapy and biologicals.

- Benchmark pratices exist, including the Finnish Asthma and Allergy programmes ${ }^{(28)}$, Integrated Care Pathways ${ }^{(10)}$ and European policies for clean air and smoking cessation.

- Collaboration of the medical community with researchers and patient organizations will be crucial for the design of optimal care pathways in the context of Precision Medicine.

\section{Precision medicine}

Precision medicine is the favored term to describe treatment targeted to the needs of individual patients on the basis of genetic, biomarker, phenotypic, or psychosocial characteristics that distinguish a given patient from other patients with similar clinical presentations (29) (30). The concept of precision medicine is not new, as the analysis of the sensization profile of allergic patients has been the diagnostic basis for the start of personalized, allergen-specific immunotherapy for decades ${ }^{(7)}$. The prospect of broadly applying precision medicine in the field of Allergy and Chronic Airways Diseases is however novel.

Precise endotyping of patients using novel methods like pro- 


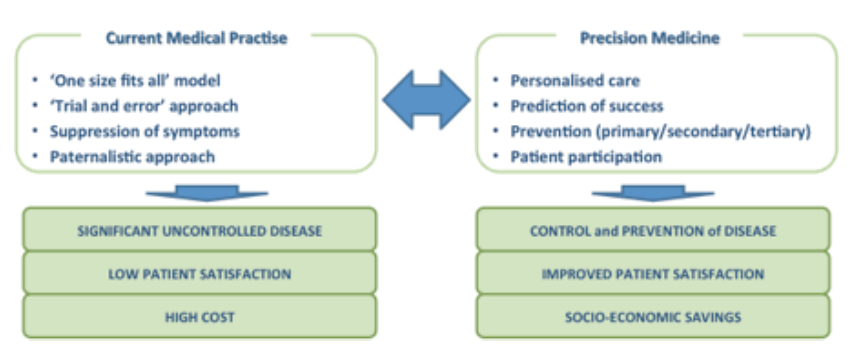

Figure 4. Outline of specific characteristics of the current medical practise versus precision medicine.

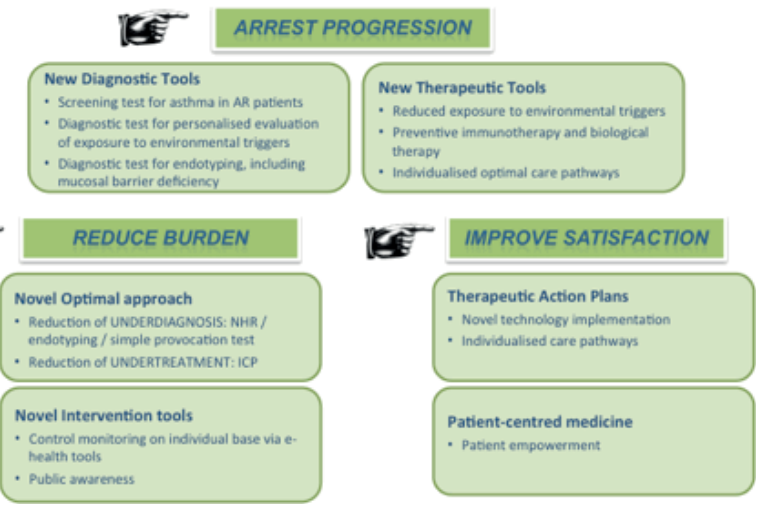

Figure 5. Aims of Precision Medicine in the field of Allergy and Chronic Airways Diseases. teomics, metabolomics, genomics, diverse cellular assays, and even mobile health technology, allows the design of therapeutic strategies with predictive, preventive, personalized and participatory aspects ${ }^{(6)}$.

The 4 P's constitute the basis of precision medicine (Figure 4).

- Personalized care is a medical practise that proposes customization of healthcare, with medical decisions, practises and/or products being tailored to the individual patient.

- Prediction of the natural progress of disease and of the success of treatment allow the medical doctor as well as the patient to decide on the best therapeutic strategy.

- Prevention of disease should be distinguished in primary, secondary and tertiary prevention. Preventive measures should be advised to prevent the disease from occurring (primary), to prevent the disease from becoming symptomatic (secondary) and to prevent from causing damage or disability (tertiary).

- Participation of the patient in the therapeutic plan is crucial for achieving good adherence and hence optimal efficacy of treatment.

\section{Specific goals of the joint initiative of European medical academies}

- Uniform recognition of Allergies and Chronic Airways Diseases as a major health problem for mankind by all stakeholders including different European Academies and Societies.

- Define a common strategy to control the Epidemic of Allergies and Chronic Airways Diseases, involving education at the level of the general public, patients and all stakeholders providing patient care. ${ }^{(22)}$

- Collaboration between medical and patient organisations in the joint initiative to curb the Epidemic of Allergies and Chronic Airways Diseases.

- Elaboration and implementation of optimal care pathways following the principles of precision medicine in Allergology and Chronic Airways Diseases, as they may lead to arrest the Epidemic and to reduce the socio-economic burden of Allergies and Chronic Airways Diseases.

\section{Proposed action plan}

- Not all patients with allergic or CRDs need precision medicine since it is unlikely to be cost-effective in the vast majority of patients who can be effectively controlled with regular treatment (for both asthma and rhinitis). However, uncontrolled patients will benefit from endotype-driven treatment.

- Economies of scale can support the uptake of the principles of Precision Medicine, with stimulation of the development of best practice centers for education and sharing expertise.

- Implementation and dissemination of the principles of precision medicine in Allergology and CRDs in best practice centers recognized for offering best care pathways and patient engagement. Best practice centers need to provide education on optimal care pathways.

- Demand for a stronger commitment of national and international governments in tackling allergies, asthma and airways diseases, supported by sharing of best practices.

- Need for active collaboration between all stakeholders involved in patient care, with a central position of patients organizations (Figure 1).

- Involvement of private companies to include allergies better in employees health programmes.

- Involvement of schools and day care providers in allergy awareness programmes. 


\section{References}

1. EAACl Global Atlas of Allergy. http://www. eaaci.org/globalatlas/GlobalAtlasAllergy.pdf [Internet]. [cited 2015 Nov 26]. Available from: http://www.eaaci.org/globalatlas/ GlobalAtlasAllergy.pdf

2. EAACI Global Atlas on Asthma. http://www. eaaci.org/attachments/Global\%20Atlas\%20 of\%20Asthma.pdf [Internet]. [cited 2015 Nov 26]. Available from: http://www.eaaci. org/attachments/Global Atlas of Asthma. pdf

3. Global Atlas of Allergic Rhinitis and Chronic Rhinosinusitis. http://eaaci.org/resources/ scientific-output/global-atlas-of-allergicrhinitis-and-chronic-rhinosinusitis.htm [Internet]. [cited 2015 Nov 26]. Available from: http://eaaci.org/globalatlas/ENT_ Atlas_web.pdf

4. Bousquet J KN. Global surveillance, prevention and control of Chronic Respiratory Diseases. A comprehensive approach. Global Alliance against Chronic Respiratory Diseases. World Health Organization. ISBN 978924156346 8. 2007:148 pages. [Internet]. [cited 2015 Nov 26]. Available from: http://www.who.int/gard/publications/GARD Book 2007.pdf

5. Samoliński B, Fronczak A, Kuna P, Akdis CA, Anto JM, Bialoszewski AZ, et al. Prevention and control of childhood asthma and allergy in the EU from the public health point of view: Polish Presidency of the European Union. Allergy. 2012 Jun;67(6):726-31.

6. Collins FS, Varmus $H$. A New Initiative on Precision Medicine. N Engl J Med. 2015 Jan 30;372(9):793-5.

7. Canonica GW, Bachert C, Hellings P, Ryan D, Valovirta E, Wickman M, et al. Allergen Immunotherapy (AIT): a prototype of Precision Medicine. World Allergy Organ J. BioMed Central Ltd; 2015 Jan 10;8(1):31.

8. Bousquet J, Schunemann HJ, Fonseca J, Samolinski B, Bachert C, Canonica GW, et al MACVIA-ARIA Sentinel Network for allergic rhinitis (MASK-rhinitis): The new generation guideline implementation. Allergy. $2015 \mathrm{Jul}$ 4;70(11):1372-92.

9. Bieber T. Stratified Medicine: A New Challenge for Academia, Industry, Regulators and Patients. Future Medicine Ltd; 2013. 75 p.

10. Bousquet J, Addis A, Adcock I, Agache I, Agusti A, Alonso A, et al. Integrated care pathways for airway diseases (AIRWAYSICPs). Eur Respir J. 2014 Aug;44(2):304-23.

11. Bousquet J, Michel J-P, Strandberg T, Crooks G, lakovidis I, Iglesia M. The European Innovation Partnership on Active and Healthy Ageing: The European geriatric medicine introduces the EIP on AHA column. Elsevier Masson; 2014.

12. Deliu M, Belgrave D, Simpson A, Murray CS, Kerry G, Custovic A. Impact of rhinitis on asthma severity in school-age children. Allergy. 2014 Nov;69(11):1515-21.

13. 1Agache I, Sugita K, Morita H, Akdis M, Akdis C a. The Complex Type 2 Endotype in Allergy and Asthma: From Laboratory to Bedside. Curr Allergy Asthma Rep. 2015;15(6):29.

14. Morais-Almeida $M$, Pite $H$, Pereira AM, Todo-Bom A, Nunes C, Bousquet J, et al. Prevalence and classification of rhinitis in the elderly: a nationwide survey in Portugal. Allergy. 2013 Sep;68(9):1150-7.

15. Bousquet J, Khaltaev N, Cruz AA, Denburg J, Fokkens WJ, Togias A, et al. Allergic Rhinitis and its Impact on Asthma (ARIA) 2008 update (in collaboration with the World Health Organization, GA(2)LEN and AllerGen). Allergy. 2008 Apr;63 Suppl 8:8160.

16. Hellings PW, Fokkens WJ, Akdis C, Bachert C, Cingi C, Dietz de Loos D, et al. Uncontrolled allergic rhinitis and chronic rhinosinusitis: where do we stand today? Allergy. 2013 Jan;68(1):1-7.

17. Vuurman EFPM, Vuurman LL, Lutgens I, Kremer B. Allergic rhinitis is a risk factor for traffic safety. Allergy. 2014 Jul;69(7):906-12.

18. Vandenplas O, D'Alpaos V, Van Brussel P. Rhinitis and its impact on work. Curr Opin Allergy Clin Immunol. 2008 Apr;8(2):145-9.

19. Muraro A, Clark A, Beyer K, Borrego LM, Borres M, Lødrup Carlsen KC, et al. The management of the allergic child at school: EAACI/GA2LEN Task Force on the allergic child at school. Allergy. Blackwell Publishing Ltd; 2010 Jun 1;65(6):681-9.

20. Zuberbier T, Lötvall J, Simoens S, Subramanian S V, Church MK. Economic burden of inadequate management of allergic diseases in the European Union: a GA(2) LEN review. Allergy. 2014 Oct;69(10):1275-9.

21. Prokopakis EP, Vlastos IM, Ferguson BJ, Scadding G, Kawauchi H, Georgalas C, et al. SCUAD and chronic rhinosinusitis. Reinforcing hypothesis driven research in difficult cases. Rhinology. Netherlands; 2014 Mar;52(1):3-8.

22. EAACI Strategic Program- 2015-2017 http:// www.eaaci.org/organisation/eaaci-strategic-programme/2013-2015.html [Internet]. [cited 2015 Nov 26]. Available from: http:// www.eaaci.org/organisation/eaaci-strategic-programme/2013-2015.html

23. Bousquet J, Anto JM, Wickman M, Keil T, Valenta R, Haahtela T, et al. Are allergic multimorbidities and IgE polysensitization associated with the persistence or re-occurrence of foetal type 2 signalling? The MeDALL hypothesis. Allergy. 2015 Sep;70(9):1062-78.

24. Ardern-Jones MR, Bieber T. Biomarkers in atopic dermatitis: it is time to stratify. $\mathrm{Br} J$ Dermatol. 2014 Aug;171(2):207-8.

25. Alvarado MI, Jimeno L, De La Torre F, Boissy P, Rivas B, Lázaro MJ, et al. Profilin as a severe food allergen in allergic patients overexposed to grass pollen. Allergy. 2014 Aug 14;

26. Moreno C, Justicia JL, Quiralte J, MorenoAncillo A, Iglesias-Cadarso A, Torrecillas M, et al. Olive, grass or both? Molecular diagnosis for the allergen immunotherapy selection in polysensitized pollinic patients. Allergy. 2014 Oct;69(10):1357-63.

27. Van Gerven L, Boeckxstaens $G$, Jorissen M, Fokkens W, Hellings PW. Short-time cold dry air exposure: a useful diagnostic tool for nasal hyperresponsiveness. Laryngoscope. 2012 Dec;122(12):2615-20.

28. Haahtela T, von Hertzen L, Mäkelä M, Hannuksela M. Finnish Allergy Programme 2008-2018--time to act and change the course. Allergy. 2008 Jun;63(6):634-45.

29. Jameson JL, Longo DL. Precision medicine-personalized, problematic, and promising. N Engl J Med. 2015 Jun 4;372(23):2229-34.

30. Bieber T. Atopic dermatitis 2.0: from the clinical phenotype to the molecular taxonomy and stratified medicine. Allergy. 2012 Dec;67(12):1475-82. I

\section{Peter W. Hellings}

Secretary-General of EAACI

EAACI Headquarters

Hagenholzstrasse 111

3rd Floor

8050 Zurich

Switzerland

E-mail: peter.hellings@uzleuven.be 